\title{
The New Frontier of Public Health Education
}

\author{
David Birnbaum, PhD, MPH \\ Adjunct Professor, UBC School of Population \& Public Health \\ Kathryn Gretsinger \\ Instructor, UBC Graduate School of Journalism \\ Ursula Ellis, MLIS \\ Reference Librarian, UBC Woodward Library
}

\begin{abstract}
Purpose - To describe the experience and educational benefits of a course that has several unique educational design features.

Design/methodology/approach - Narrative description of faculty and student experience from participants in a flipped-instructional-design inter-professional education course.

Findings - "Improving Public Health - An Interprofessional Approach to Designing and Implementing Effective Interventions" is an undergraduate public health course open to students regardless of background. Its student activities mirror the real-life tasks and challenges of working in a public health agency, including: team-building and leadership; problem and project definition and prioritization; evidence-finding and critical appraisal; written and oral presentation; and press interviews. Students successfully developed project proposals to address real problems in a wide range of communities and settings, and refined those proposals through interaction with professionals from population and public health, journalism and library sciences. Practical implications - Undergraduate public health education is a relatively new endeavor, and experience with this new approach may be of value to other educators.

Originality/value - Students in this course, journalism graduate students who conducted mock interviews with them, and instructors who oversaw the course all describe unique aspects and related personal benefit from this novel approach.

Keywords -

Paper type - Case Study
\end{abstract}

Public health has joined the ranks of allied health professions for which certification by examination is available (Foster, 2016). To succeed on a certification exam that spans knowledge areas consistent with historic expectations and recent job task analysis, students need courses in which theory and practice match skills needed for career success. Those skills include abilities in defining and measuring health problems; finding and critically appraising pertinent information; planning; communicating orally and in written formats for a range of audiences; networking and advocacy; and more (Briedenbach and Irwin, 2016). A recent meta-analysis shows that coursework employing active learning strategies produces better results than traditional lecture formats (Freeman et al., 2104). The University of British Columbia School of Population and Public Health offers a course that meets these requirements through novel interprofessional approaches. It is designed with a "flipped" instructional approach, meeting in a 
classroom approximately once a month but otherwise having individuals and teams work through lesson materials that are provided on-line.

SPPH 410 (Improving Public Health - An Interprofessional Approach to Designing and Implementing Effective Interventions) is open to all interested students regardless of background. In the January 2016 term, 49 students participated with backgrounds spanning biology, commerce, kinesiology, nursing, nutrition, paramedics, pharmacology, psychology or other undergraduate programs. The only thing they shared in common was an interest in coursework focused on teamwork and public health. Briefly, the course begins by discussing the scope of work encompassed by public health agencies, has students organize themselves in teams of 5-10 around broad themes of mutual interest (e.g. chronic diseases, infectious diseases, maternal and child health, health promotion, etc.), and then guides teams through self-directed learning as they progress through:

- $\quad$ selection and oral presentation of three potential intervention ideas;

- selection of the idea most likely to succeed after feed-back from the class;

- researching and writing a graded first-draft;

- refining and writing a graded final-draft;

- assessing as a team the strengths and areas for improvement of individual team members, using a format adapted from the UBC School of Medicine rubric for Preparation, Participation and Professional Behaviour categories;

- presenting a final, graded oral report describing their project proposal.

More information is available at http://spph.ubc.ca/courses/undergraduate-courses/

Several aspects of this course are novel.

- Early on, the students were assigned to select and briefly research three potential project topics (which they would then describe in oral presentations, and after receiving feedback from classroom discussion would select the best one for their project). This not only gave students practice in making the kind of presentations typical of professional conference sessions, but revealed that despite an introductory presentation by a reference librarian they nearly all were failing to make adequate use of library resources.

- After the presentation session, all students made better use of reference librarian guidance and, in turn, the reference librarian had an opportunity to follow the students' progress and see how her help was making a difference.

- As students neared the due date for their formal project report, we surprised them with mock media interviews. That session started by explaining anyone in a public health project or program lead position might answer their telephone and suddenly find themselves talking to a reporter. We then paired graduate students from UBC's School of Journalism with the project teams, had the journalism students conduct an interview at start of the hour, then debrief the class by explaining what sort of stories could likely emerge from the information conveyed and communication skills exhibited; finally, we ended in discussion that provided feed-back on realistic expectations as well as best practices in the essential working relationship between journalists and public health science professionals.

- Both SPPH 410 students and the journalism students said they enjoyed the experience and learned from it. Several SPPH 410 students indicated that the interview revealed weaknesses in their project report along with ways they can 
improve their communication of those points to strengthen the report. One of the journalism students indicated interest in taking SPPH 410 next time it is offered.

- According to journalism students, this opportunity reinforced that "it's important to ask specific questions in order to get specific answers", "it's important to tell people you're interviewing what you DON'T need to know" (i.e. what you already know about the subject and don't need to confirm), and "it's much more difficult [a group] than interviewing one-on-one, especially with people who haven't had experience dealing with "the media'" so it is important to quickly "try and get people more comfortable...next time I might direct questions to specific people so that it's not always the same one or two people talking. "

- The journalism students also expressed interest in working with public health students in order to fully explore their research or project conclusions and consider ways to share that information in a journalistic format. It became clear that journalism students think in stories whereas public health students think in outcomes. Journalism students ask questions and rely on sources to find answers, while public health students ask questions, posit conclusions and rely on their own research data to provide answers or explanations.

A good problem for problem-based learning must have several attributes (Dolmans et al., 1997). These are:

1. Contents should adapt well to students' prior knowledge;

2. Should contain several cues that prompt students to elaborate;

3. Context should be relevant to the students' future profession(s);

4. Relevant basic sciences concepts should encourage integration of knowledge;

5. Should encourage students to generate learning issues and conduct literature searches;

6. Format should enhance interest by sustaining discussion and exploring alternative solutions;

7. Should match one or more of the faculty (lesson plan) objectives. SPPH 410 achieves these requirements by letting students self-organize into work teams based on shared areas of interest; facilitating initial team-building so that team members make each other known to the group and then taking turns from week-to-week being team leader; select, research and formulate the best possible solutions to a specific population health problem; and contribute to group learning in both the team meetings and classroom sessions. Core assigned readings provide a general framework, but only a starting point while teams start identifying specific information needs unique to their individual projects. Core course materials illustrate different styles of team structure and functioning possible, but serve only as a starting point while teams refine their effectiveness through periodic use of formal self-evaluation tools.

To encourage inter-professional education (IPE), UBC offers an IPE Passport Program (http://passport.health.ubc.ca/) through Office of the Vice-Provost Health. This program offers faculties a bridge to overcome isolating barriers; instructors a rubric for course design (awarding points for various elements and depth of experience consistent with achieving inter-professional skills learning objectives); and students a resource for identifying upcoming opportunities and tracking completion of point-bearing activities. SPPH 410 is one of nine undergraduate public health courses now offered by the School of Population and Public Health that qualify for the IPE Passport Program (http://spph.ubc.ca/courses/undergraduate-courses/). SPPH 410 is the first 
course under the IPE Passport Program to reach beyond health science faculties, engaging the Graduate School of Journalism. Students in journalism come from a variety of disciplinary backgrounds. They are working to become subject area experts and professional practice journalists. This experiential learning opportunity provides students with an opportunity to use their journalistic skills and more fully understand the challenges in taking complex research and translating it for a general audience. This is a direct way for students to become journalistic practitioners within a supported academic setting.

Evidence for the efficacy of public health interventions is not always clear-cut or easy to find. Often undergraduate students have minimal exposure to literature searching beyond quick keyword searches in Google Scholar or PubMed. SPPH 410 afforded students an opportunity to build more advanced search strategies using Ovid Medline. Using Medical Subject Headings, subheadings, and truncation enabled them to increase the relevance and comprehensiveness of their search results. In the classroom session and in consultations with students, the librarian also introduced other literature databases such as PAIS and EMBASE, and relevant websites.

Students also learned more about what types of information are likely to be found in the published literature, and what types require alternate means to locate. For instance, one group sought data on awareness about a health issue among UBC students. After consultation with the librarian, they reframed their search to find published articles with data from similar universities, connected with local contacts about potential unpublished data, and chose to develop their own survey. Knowing how to frame questions and where to source quality information is a critical skill sometimes lacking in graduates once they enter the workforce (Head, 2012). SPPH 410 students' experience with searching to support needs assessments and to discover and evaluate existing public health interventions will serve them well in a variety of work environments.

Undergraduate education in public health is a relatively new development, and it is as yet unclear how it should best be delivered to serve realistic purposes. If offered as a degree program, then for those to whom early specialization appeals it is incumbent upon schools of public health to consider both how this impacts graduate-level courses (since students may object to having to repeat course content) and career development (since graduate degrees are the norm in hiring and promoting public health professionals). If offered as a certificate program, then this could give undergraduates additional credentials for graduate school application, but graduate schools still need to avoid duplication in course requirements. If offered only as individual courses, then these could help whet the appetite towards public health as a career, as well as give other students aiming toward different career paths a better understanding of public health, but only if realistic course experiences are exciting. SPPH does not duplicate the depth of coverage in public health graduate-level methods courses, and according to student evaluations succeeded as a realistic and engaging experience that advanced participants" "soft" skills for success. Typical comments in the students' course evaluation results are:

- This course was very useful in developing strong team building skills. The skills learned can be applied in many real world scenarios that involve team efforts in making programs, running meetings, and proposals.

- The course content was very practical and helpful for me, as I am considering pursuing a degree in SPPH. It provided me with a great look at the work of [public health] workers, and provided us the chance to improve on our leadership and team-cooperation skills. 
- Having completed this course I felt a sense of accomplishment as we have identified important healthcare issue that needs to be addressed and actually came up with an actual intervention to solve the problem.

○ This pride of accomplishment also was noted by the journalism students, who mentioned how the public health students being personally invested in their projects made the journalism students aware of how the emotional self ought to be considered when interviewing subjects about their work.

- It's a great course to take with friends, especially those you trust you will work well with. If you are meeting new people in this course, it is an excellent way to build a team based work ethic, interpersonal, self-sufficiency in producing good work.

- The realistic nature of the course, I liked how similar it was to the actual experience of implementing interventions in the field. Moreover, the surprise addition of the Journalism students was an unanticipated challenge that I really enjoyed participating in.

- I think the report was a very useful assignment, the learning curve was steep but I appreciate the knowledge and skills developed in this process.

\section{References:}

Breidenbach, D.H. and Irwin, Z. (2016), "A Job Analysis of the Certified in Public Health, Conducted for the National Board of Public Health Examiners", Applied Measurement Professionals Inc. and National Board of Public Health Examiners, Aloathe Kansas (AMP) and Washington DC (NBPHE), January, available at https://nbphe.org/CPHjta.cfm (accessed 16 March 2016)

Dolmans, D.H.J.M., Snellen-Balendong, H., Wolfhagen, I.H.A.P. and van der Vleuten, C.P.M. (1997), "Seven principles of effective case design for a problem-based curriculum", Medical Teacher, Vol. 19 No. 3, pp. 185-189.

Foster, A. (2016), "Certified in public health program: credentialing public health leaders", International Journal of Health Governance, Vol. 21 No.1 , pp. 26-34.

Freeman, S., Eddy, S.L., McDonough, M., Smith, M.K., Okoroafor, N., Jordt, H. and Wenderoth, M.P. (2014), "Active learning increases student performance in science, engineering, and mathematics", PNAS, Vol. 111 No. 23, pp. 8410-8415, available at http://www.pnas.org/content/111/23/8410.full (accessed 9 March 2016).

Head, A.J. (2012), "Learning curve: how college graduates solve information problems once they join the workplace", Project Information Literacy Research Report, October 16, available at http://projectinfolit.org/images/pdfs/pil_fall2012_workplacestudy_fullreport_revised.pdf (accessed March 21, 2016). 